At right, Torpedos are dragged in nonwheel furrows at the UC Davis test site.

Below,Blaine Hanson inspects concrete-filled torpedoes used in the San Joaquin Valley.

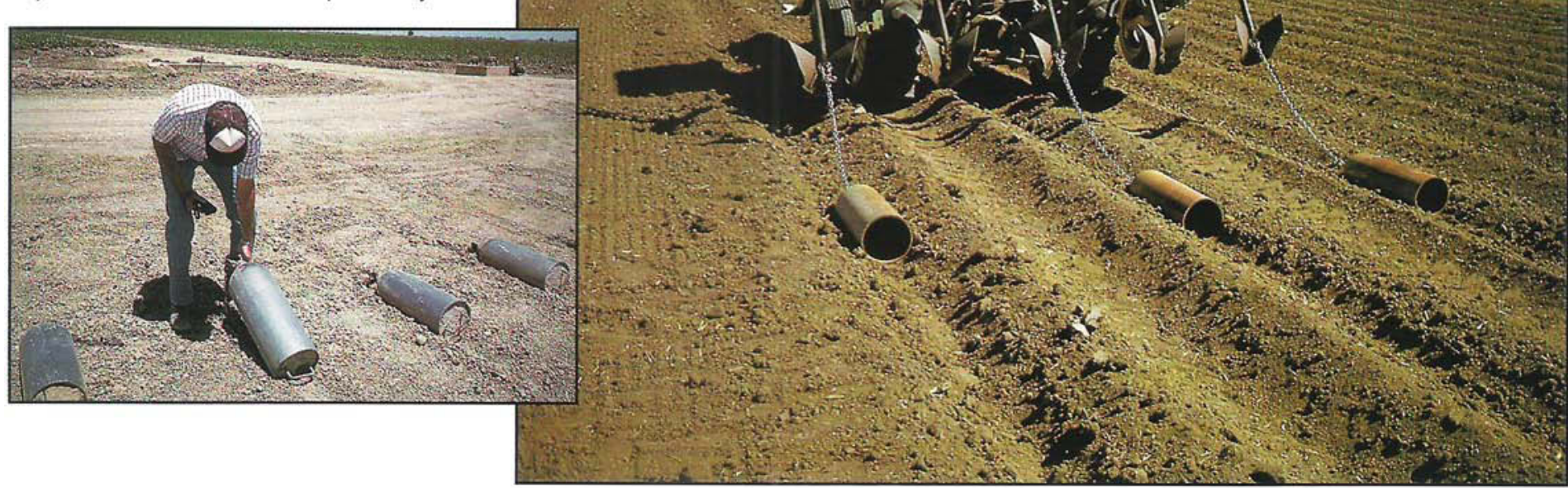

\section{Furrow torpedoes improve irrigation water advance}

\author{
Lawrence J. Schwankl $\square$ Blaine R. Hanson $\square$ Anthanasios Panoras
}

\section{To increase irrigation uniformity and to reduce drainage volumes, some San Joaquin Valley growers drag weighted steel cylinders (tor- pedoes) in furrows before irrigation to speed the advance of water across the field. The effectiveness of this practice and the reasons it works have been investigated.}

In much of the San Joaquin Valley, where there is no outlet for irrigation drainage water, growers have two choices: (1) adopting disposal methods that include establishing evaporation basins, employing agroforestry (such as applying drainwater to grow eucalyptus), and reusing the drainwater and/or (2) improving furrow/border irrigation and irrigation scheduling or converting to pressurized sprinkler or drip irrigation systems.

Irrigating with improved furrow/border irrigation techniques or with pressurized irrigation systems decreases drainage volumes because irrigation water is applied more uniformly, resulting in less water being used to adequately irrigate all parts of a field.

A major cause of nonuniformity in furrow irrigation is the time it takes to ad- vance water across the field (advance time). The advance time is the additional time water is infiltating at the head of the field versus the tail of the field. Frequently, the head of the field is overirrigated so that the tail of the field can be adequately irrigated. In turn, nonuniform water application leads to deep percolation (drainage water). An objective, therefore, of furrow irrigation is to minimize the infiltration time difference between the head and tail of the field by using one of several techniques, including reducing the length of the field and increasing the rate at which water advances across the field.

The rate water is advanced can be speeded by compacting and smoothing the furrow. This is evident in furrows that have had a tractor wheel run in them (wheel furrows) versus those with none (nonwheel furrows). Water advance is significantly faster in wheel furrows. Because running a tractor wheel down every furrow in a field is impractical, some growers in the San Joaquin Valley drag "torpedoes" (weighted steel cylinders) in the furrows to smooth, compact, and change the shape of the furrows; thus, the advance rate of water across the field is increased.

This study was undertaken to determine the effects of using torpedoes on advancing irrigation water, water infiltration, furrow shape, and furrow roughness.

\section{Methods}

Three sites were chosen to investigate torpedo effects: a site in Fresno County (Fresno County No. 1) with Panoche fine sandy loam soil and furrows 2,600 feet (790 meters) long; a site in Fresno County (Fresno County No. 2) with a Westhaven clay loam soil and furrows 1,150 feet (350 $\mathrm{m})$ long, and a site at the UC Davis Campbell Tract with a silt loam soil and furrows 1,000 feet $(305 \mathrm{~m})$ long.

Each site was divided into portions of the field where torpedoes were dragged in the furrows and portions where furrows were not torpedoed. This allowed side-byside comparisons. At each site, measurements of pre-irrigation furrow cross-sectional shape and roughness were taken at 82 -foot $(25-\mathrm{m})$ intervals over selected sections of both torpedoed and nontorpedoed furrows. These sites were measured again following irrigation. Each site was irrigated, with a detailed evaluation performed on both selected torpedoed and nontorpedoed sections. Evaluation measurements included monitoring furrow inflow rates, measuring steady-state intake rates by monitoring inflow and outflow with flumes placed in individual furrows until the furrow outflow rate became constant, and measuring advance times of water at specified distances down the furrow.

\section{Torpedo effects}

Furrow cross section. Analysis of furrow cross-sectional shape measurements revealed that the furrow cross-sectional area available for shallow-depth water flow, which occurs as water advances down the furrow, is increased by dragging torpedoes in the furrow. This was evident at all three sites investigated (fig. 1). Use of 

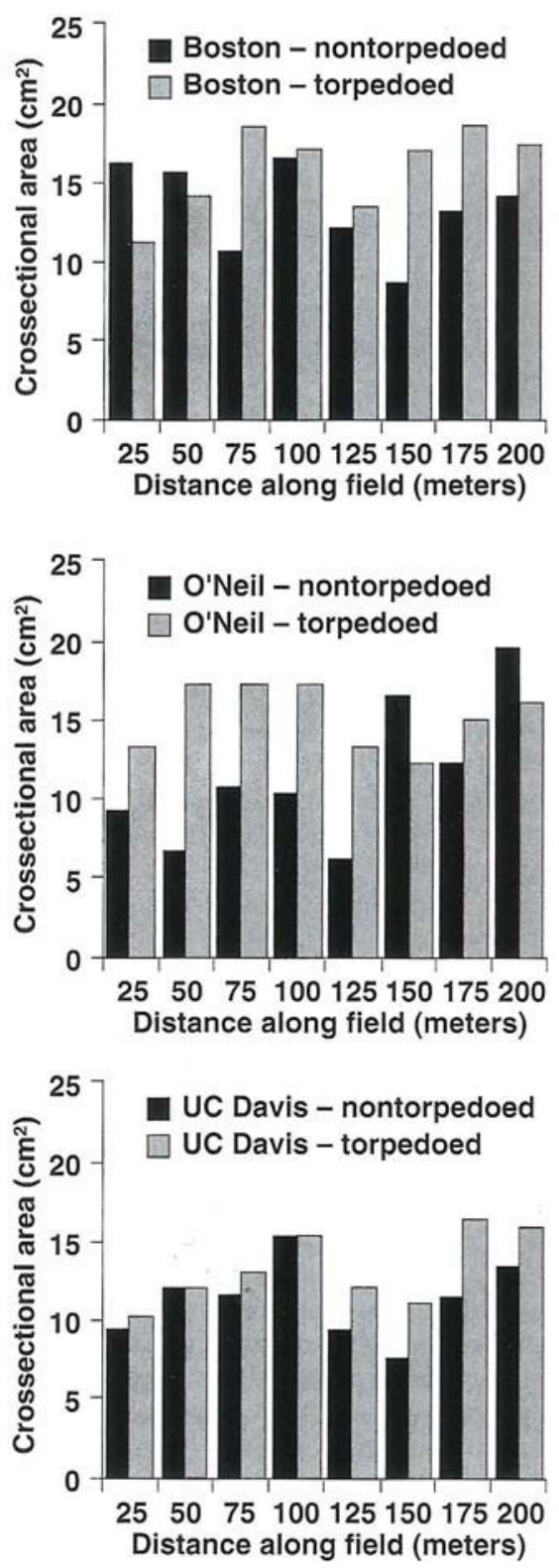

Fig. 1. The pre-irrigation cross-sectional area at the $2-\mathrm{cm}(0.8 \mathrm{in}$.) flow depth for torpedoed and nontorpedoed furrows at three sites are compared.

the torpedoes creates a semicircular channel in the bottom of the furrow. Hydraulically, the circular-shaped channel carries water more efficiently than the original, Vshaped furrow (fig. 2)

Furrow cross-sectional shape measurements, taken after irrigation, indicated no difference in the final furrow area between torpedoed and nontorpedoed furrows. Water flowing in the furrow eroded both torpedoed and nontorpedoed furrows, resulting finally in similar furrow shapes. For equal flow deptlas, the furrow crosssectional flow area for both torpedoed and nontorpedoed furrows was substantially larger in post-irrigation furrows than in pre-irrigation furrows.
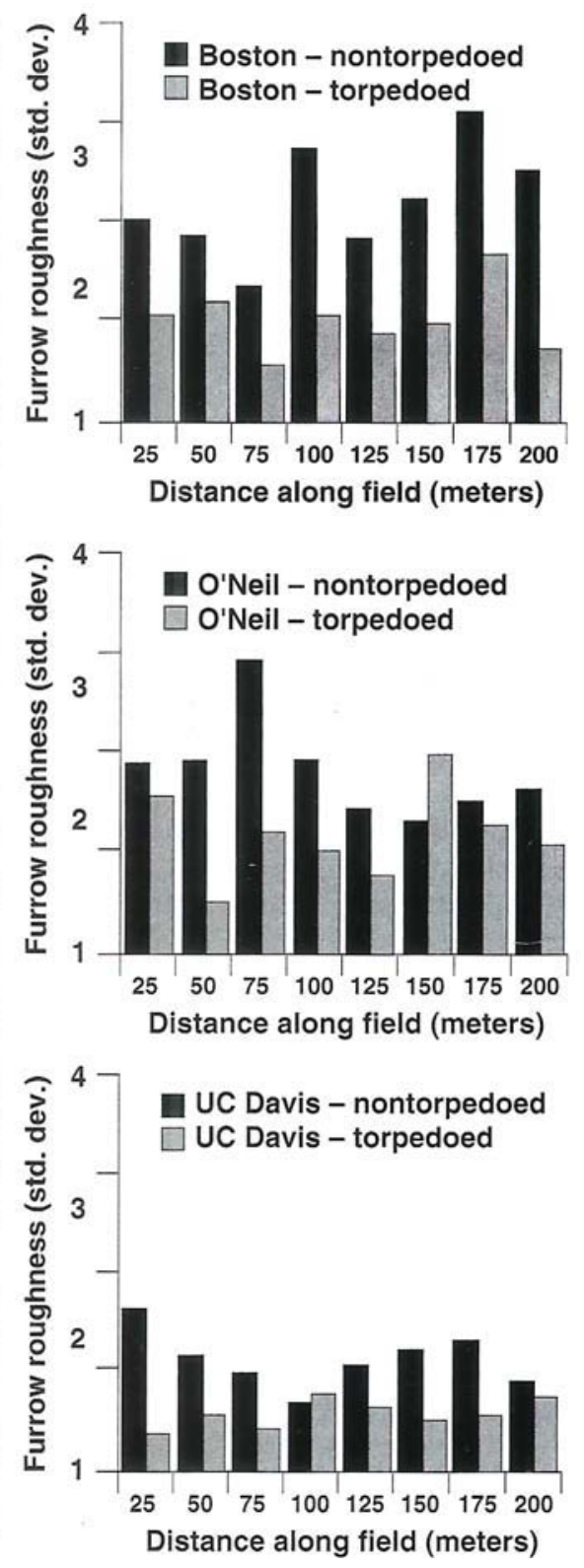

Fig. 3. The pre-irrigation furrow roughnesses of torpedoed and nontorpedoed furrows at three sites is compared.

Furrow roughness. The impact of using torpedoes on furrows is most evident when evaluating the furrow's roughness. The roughness of a channel is a measure of the frictional resistance to water flow. The rougher the furrow is, the slower and more deeply water moves along it. Thus, water advance along a rough furrow is slower than in a smoother furrow.

At all three sites evaluated, the pre-irrigation roughness of the nontorpedoed furrows was substantially greater than in the torpedoed furrows (fig. 3). The torpedo effect was most evident at the two Fresno County sites which had heavier-textured soils. Heavier soils tend to have more clods and are rougher following furrow

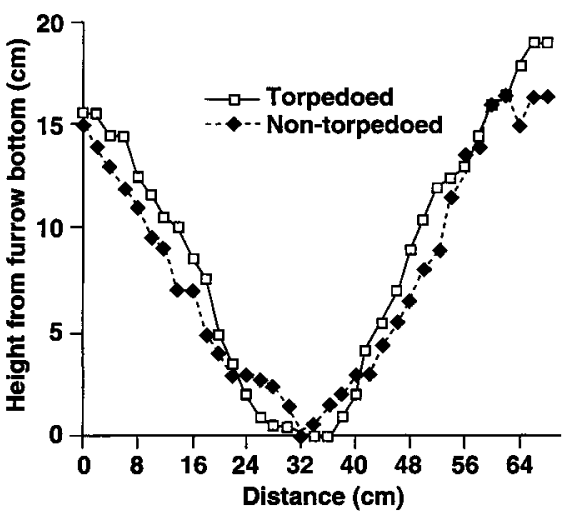

Fig. 2. Channel shapes for pre-irrigation torpedoed and nontorpedoed furrows are compared.

preparation than are lighter-textured soils. Dragging torpedoes in furrows breaks up the clods, resulting in a substantially smoother furrow.

Following irrigation, the roughness of both torpedoed and nontorpedoed furrows was statistically equivalent at both Fresno County sites. These irrigations were long - 24 hours at Fresno County No. 1 and 18 hours at Fresno County No. 2. The UC Davis site showed evidence that the post-irrigation torpedoed furrows were statistically smoother than the postirrigation nontorpedoed furrows. At UC Davis, irrigation time was 8 hours, substantially less than at the other sites. It is likely that irrigation water in the nontorpedoed furrows had less time for smoothing and reshaping at UC Davis, compared with the Fresno County sites, and that the residual effects of the torpedoes were evident at UC Davis due to the lesser irrigation time.

Advance. Evaluation at UC Davis allowed us the greatest control over furrow inflow, and therefore provided the best comparison between torpedoed and nontorpedoed furrows. At UC Davis, torpedoes were dragged in nonwheel furrows but not in wheel furrows - a common practice of growers using torpedoes in the San Joaquin Valley. Torpedoing decreased advance times in the nonwheel furrows (statistically significant at $5 \%$ level using t-test) by an average of 30\% (table 1). Water advance in wheel furrows (not torpedoed) was similar to that in torpedoed furrows, indicating that the impact of using torpedoes in furrows was similar to that of wheel traffic. In practice, torpedoing furrows would be advantageous since advancing irrigation water in wheel furrows tends to reach the end of the field before the water in nonwheel furrows and contributes significantly to tailwater runoff. For many growers, managing tailwater runoff is difficult and undesirable. 


\begin{tabular}{|c|c|c|c|c|c|c|c|}
\hline \multicolumn{5}{|c|}{$\begin{array}{c}\text { TABLE 1. Comparison of irrigation advance times (in minutes) to } 200 \text { meters at UC Davis and two } \\
\text { Fresno County sites }\end{array}$} & \multicolumn{3}{|c|}{$\begin{array}{l}\text { TABLE 2. Steady-state water intake rates in gal- } \\
\text { lons per minute per } 100 \text { feet of furrow length for } \\
\text { UC Davis and Fresno County test sites }\end{array}$} \\
\hline \multirow[b]{2}{*}{ Site } & \multicolumn{2}{|c|}{$\begin{array}{l}\text { Torpedoed } \\
\text { furrows }\end{array}$} & \multicolumn{2}{|c|}{$\begin{array}{l}\text { Nontorpedoed } \\
\text { furrows }\end{array}$} & \multirow[b]{2}{*}{ Site } & \multirow{2}{*}{$\begin{array}{l}\text { Torpedoed } \\
\text { furrows }\end{array}$} & \multirow{2}{*}{$\begin{array}{l}\text { Nontorpedoed } \\
\text { furrows }\end{array}$} \\
\hline & Avg. & $\mathrm{CV}^{*}$ & Avg. & $\mathrm{CV}$ & & & \\
\hline & \multicolumn{4}{|c|}{ 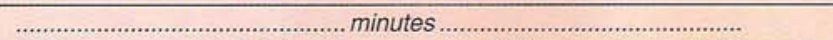 } & \multirow{2}{*}{\multicolumn{3}{|c|}{$\ldots \ldots \ldots . . .9 p m / 100 \mathrm{ft} \ldots \ldots \ldots$}} \\
\hline UC Davis & 164 & 0.146 & 230 & 0.091 & & & \\
\hline Fresno Co. No. 1 & 249 & 0.474 & 294 & 0.347 & \multirow{3}{*}{$\begin{array}{l}\text { UC Davis } \\
\text { Fresno Co. No. } 1 \\
\text { Fresno Co. No. } 2\end{array}$} & 1.10 & 1.20 \\
\hline Fresno Co. No. 2 & 560 & 0.116 & 715 & 0.210 & & 1.40 & 1.22 \\
\hline${ }^{*} \mathrm{CV}=$ coefficient 0 & & & & & & 0.10 & 0.67 \\
\hline
\end{tabular}

At the Fresno County sites, there was no statistically significant difference between furrow inflow rates to torpedoed and nontorpedoed sections. Soil cracking, evident at both Fresno County sites, particularly at Fresno County No. 2, complicated isolating the impact of torpedo use. At Fresno County No. 2, there was a statistically significant (at $5 \%$ level using t-test) difference in irrigation advance rates between torpedoed and nontorpedoed furrows (table 1). This was not true at Fresno County No. 1, where there was no statistically significant difference in irrigation advance rates between torpedoed and nontorpedoed furrows (table 1). The differences in advance rates shown in table 1 are the result of furrow torpedoing and not simply a result of differences in furrow inflow rates, an indication that use of furrow torpedoes effectively increased the advance rate of irrigation water.

Furrow infiltration. During irrigation, the water infiltration rate begins high and decreases with time until a final, constant, steady-state infiltration rate is achieved. The time required for the steady-state infiltration rate to be reached varies with soil type. At the three sites evaluated, flumes placed at the head and near the tail of the furrows allowed determination of the timing and value of the steady-state intake rate.

Table 2 shows the steady-state water intake rates for the three sites. Differences in the steady-state intake rate between torpedoed and nontorpedoed furrows were small at Fresno County No. 1 and UC Davis, and data analysis showed that these differences were not statistically significant. This suggests that the torpedoes had little effect on the steady-state intake rate of the furrow. For Fresno County No. 2 , however, differences in intake rate were substantial and were statistically significant, indicating that torpedoes reduced the furrow's final intake rate. The infiltration measurements taken did not allow determination of furrow torpedoing impacts on the water intake rate before infiltration reached the steady-state rate. Infiltration characteristics during this period merit attention because a decrease in the furrow intake rate can result in faster water advancement along the field.

The torpedo effect on the soil infiltration rate may depend on the surface soil moisture content at the time of torpedoing. At the Fresno County No. 1 and UC Davis sites, observations at the time of torpedoing indicated that the soil was probably air-dry. Thus, while use of the torpedo smoothed the soil surface, soil compaction was apparently minimal. We hypothesize, however, that because of rainfall shortly before torpedoing, the soil surface at Fresno County No. 2 may have been wetter at the time of torpedoing, resulting in greater soil compaction and a lower intake rate.

\section{Additional observations}

Although not measured in this study, it has been the authors' observation that soil moisture content at the time the field is torpedoed has an impact on both furrow cross-sectional shape and furrow roughness. If torpedoes are dragged when the soil is slightly moist, the result is a more definite, semicircular channel with sides that do not slough back into the furrow bottom. The resulting furrow is also smoother with the furrow bottom being almost slick in appearance.

It is speculation, backed by field observations, that using torpedoes when the soil surface is moist may also cause a "slicking" of the soil surface, resulting in a reduced water intake rate in the furrow. Therefore, dragging torpedoes when the soil surface is moist tends to accentuate the impact of torpedoes. Torpedoing a dry furrow tends to break up clods, reducing furrow roughness, but it does not leave as definite a semicircular channel.

Torpedo shape and weight also appear to play a role in their effectiveness. In practice, growers use torpedoes that vary in diameter and weight. The authors have seen in use torpedoes ranging in diameter from 6 to 12 inches, in length from 18 inches to 4 feet, and in weight from hollow torpedoes to those filled completely with concrete. Westlands Water District recommends for use as a torpedo a 3.5-foot-long, 10-inch-diameter steel pipe, domed at the front end and filled with concrete. This heavier torpedo more effectively smoothes furrows and "tracks" better when being towed, but its additional weight makes handling more difficult.

Currently, some growers make a separate equipment pass through the field to torpedo the furrows. It is suggested, where possible, that furrow torpedoing be done in conjunction with other furrow preparation operations.

\section{Summary}

Use of furrow torpedoes effectively smoothes and changes furrow shape before irrigation. The resulting cross-sectional shape change and reduced furrow surface roughness increases the water advance rate during irrigation - a positive result because the uniform water application is thereby improved. Improved irrigation uniformity allows the water manager to more closely match the crop's water demands and to minimize water losses due to deep percolation (drainage).

At one site, torpedoing reduced the furrow's steady-state water infiltration rate. A similar phenomenon was not observed at the other two sites investigated. An increase in the irrigation advance rate of torpedoed furrows, ranging from 15 to $30 \%$, was noted at each site evaluated. Torpedoed, nonwheel furrows had water advance characteristics similar to wheel furrows. Torpedoing nonwheel furrows therefore resulted in more equal water advance rates among furrows.

L. J. Schwankl and B. R. Hanson are Extension Specialists, Department of Land, Air and Water Resources, UC Davis, and A. Panoras is Irrigation Specialist, Land Reclamation Institute, Greece.

The authors would like to thank the Committee on the Relation of Energy to Agriculture (CREA) for financial support of this project and Tracy Slavin, Irrigation Specialist, Westlands Water District, for his assistance. They would also like to acknowledge the cooperation of Boston Farms and O'Neil Farms of Fresno County. 